\title{
Population-based Study of Medulloblastoma: Outcomes in Alberta from 1975 to 1996
}

\author{
Gloria Roldán, Penny Brasher, Giacomo Vecil, Donna Senger, \\ Barry Rewcastle, Gregory Cairncross, Peter Forsyth*, Mark Hamilton
}

\begin{abstract}
Background: The purpose of this study was to determine incidence, survival rate, and prognostic factors as well as the frequency of Collins' Law Violators (CLVs) in an unselected population of medulloblastoma patients. Collins' Law dictates that 'cure' of a child with a tumor occurs after a period that includes the child's age at diagnosis plus 9 months. Methods: Using the Alberta Cancer Registry a population-based review identified 49 patients with medulloblastoma (19 adults, 30 children) diagnosed from $1975-96$. Pathology was reviewed in all cases. All patients had surgical resection, followed by radiotherapy in 47 patients and chemotherapy in 17. Results: The overall 5-year survival was 50\%. There was a trend for the extent of resection to be associated with a longer survival (Long rank test, $\mathrm{p}<0.06$ ) but this was not significant. Tumor recurrence occurred a median of 22.4 months (range, 6.4-192.3) after diagnosis and median survival after recurrence was 9.3 months (range, 0.4-64.9). The survival curve did not appear to plateau but was affected by tumor-related deaths in $3(21.4 \%)$ of the 21 long-term survivors diagnosed in childhood. These three patients had recurrences a mean of 11.7 years after diagnosis and are designated as CLVs. Conclusions: The survival rate in an unselected population of patients with medulloblastoma is poor. Aggressive resection of the tumors prolongs survival. The Collins' Law Violators were relatively common and we suggest this concept be abandoned in medulloblastoma.
\end{abstract}

RÉSUMÉ: Étude de population sur le médulloblastome en Alberta de 1975 à 1996. Contexte : Le but de cette étude était d'évaluer l'incidence, le taux de survie et les facteurs influençant le pronostic ainsi que la fréquence des contrevenants à la loi de Collins dans une population non sélectionnée de patients atteints de médulloblastome. Selon la loi de Collins, un enfant atteint d'une tumeur est guéri après un temps défini par l'âge de l'enfant au moment du diagnostic plus 9 mois. Méthodes : Nous avons identifié 49 patients atteints de médulloblastome (19 adultes et 30 enfants) dans le Alberta Cancer Registry, entre 1975 et 1996. L'anatomopathologie a été révisée dans tous les cas. Tous les patients avaient subi une résection chirurgicale suivie de radiothérapie chez 47 patients et de chimiothérapie chez 17 patients. Résultats : La survie globale à 5 ans était de $50 \%$. La longueur de la survie avait tendance à être associée à l'étendue de la chirurgie, sans atteindre le seuil de la signification statistique (Long rank test, $\mathrm{p}<0,06)$. La médiane de survie sans récidive était de 22,4 mois (écart de 6,4 à 192,3 mois) après le diagnostic et la survie médiane après la récidive était de 9,3 mois (écart de 0,4 à 64,9 mois). La courbe de suivie ne semblait pas atteindre de plateau et elle était influencée par le décès dû à la tumeur chez 3 des 21 survivants à long terme dont le diagnostic avait été posé dans l'enfance. La moyenne de survie sans récidive chez ces 3 patients était de 11,7 ans après le diagnostic et donc ils sont des contrevenants à la loi de Collins. Conclusions : Le taux de survie dans une population non sélectionnée de patients atteints de médulloblastome est faible. Une résection agressive de la tumeur prolonge la survie. Les contrevenants à la loi de Collins étaient relativement fréquents et nous proposons que ce concept soit abandonné en ce qui concerne le médulloblastome.

Can. J. Neurol. Sci. 2008; 35: 210-215

Medulloblastoma is the most common malignant brain tumor of the central nervous system (CNS) in children, accounting for approximately $20 \%$ of all pediatric brain tumors. ${ }^{1,2}$ It is comparatively rare in adults, with a reported incidence rate of $0.05 / 100,000$ per year, accounting for $1 \%$ of all primary tumors of the CNS.,4 There are few reported studies concerning adults and when reported, adults constitute a small part of the study group. ${ }^{5-7}$ Previous studies of outcomes in medulloblastoma patients are based on case series or institutional experiences which were limited by referral and selection biases. ${ }^{8,9}$ To our knowledge, there are no population-based studies of children and
From the Department of Clinical Neurosciences (GR, DS, BR, GC, PF, MH), Department of Anatomic Pathology (BR), Division of Neurosurgery (MH), Foothills Medical Centre, University of Calgary; Department of Oncology (GR, PB, DS, GC, PF), Clark Smith Integrated Brain Tumor Cancer Centre (GR, GC, PF, MH), Division of Population Health and Information (PB), Heritage Medical Research Building, Calgary, Alberta, Canada; Department of Neurosurgery (GV), University of Texas, Health Science Center, San Antonio, Texas, USA.

Received January 2, 2007. Final Revisions Submitted December 21, 2007. Corresponding Author*: Peter Forsyth, Clark Smith Brain Tumor Center, Rm. 2AA19 Health Research Innovation Center, 3330 Hospital Drive NW, Calgary, Alberta, $\mathrm{T} 2 \mathrm{~N} 4 \mathrm{~N} 1$, Canada. 
adults with medulloblastoma in which the histologic sections were reviewed by a single neuropathologist.

Over the past several decades the survival for medulloblastoma in children has improved significantly. The overall survival rate in children with average and high risk medulloblastoma after surgery, cerebrospinal irradiation and adjuvant chemotherapy is approximately $85 \%$ and $70 \%$ at five years, respectively. ${ }^{10,11}$ Taking into account the side effects of radiotherapy in the neurodevelopment of children, systemic treatment has been evaluated to delay the indication of radiotherapy in small children, or even as an intent to avoid it. ${ }^{12-15}$

In 1955, Collins made the observation that tumor recurrence in children with Wilms' tumor usually occurred within a period of the child's age plus nine months. ${ }^{16}$ After that time children were considered cured of the tumor. This concept of a "period of risk" for recurrence was later applied to a variety of tumors in children and became known as Collins' Law. ${ }^{17}$ This law has been a successful predictor of survival for some children with brain tumor and a poor predictor for others. ${ }^{18-20}$

We noted three unexpected issues while treating medulloblastoma patients, which prompted us to undertake this study. First, we encountered a patient (diagnosed as a child) presenting with a recurrence a very long time after the initial diagnosis thus "violating" Collins Law [hence, the designation "Collin's Law Violator" (CLV)]. Second, we were following a larger portion of adults in our practice than has been reported in the literature. Third, the survival rate in our patient population was not as favorable as published reports and "cure" occurred less commonly. Our review identified that there are no studies of outcomes of medulloblastomas in an entire population in which charts and histological sections were re-reviewed to assure the accuracy of the clinical and histological information. For these reasons we undertook this study of outcomes in medulloblastoma patients in an unselected population-based study.

The objectives of this study include the incidence, natural history, clinical, imaging, and pathological characteristics as well as treatment outcomes in an unselected population of medulloblastoma patients. We also wanted to determine how commonly medulloblastoma patients violated the Collins' Law.

\section{Patients and Methods}

\section{Case Ascertainment}

Patients with diagnosis of medulloblastoma, or primitive neuroectodermal tumor with topographic codes for the cerebellum, brainstem or fourth ventricle (International Classification of Disease for Oncology Version II Topography codes c71.6-c71.7, and morphology codes 94703-94733) 21,22 were identified in the Alberta Cancer Registry. The Alberta Cancer Registry is a population-based cancer registry for the province of Alberta (population 2.8 million in 1996), which was established by an Act of the Provincial Legislature and has been operational since 1941. Endorsing legislation is in place requiring all physicians, hospitals, pathologic laboratories, radiographic facilities and cancer treatment centers to participate in registering all patients with a clinical, radiographic or histologic diagnosis of cancer (including those diagnosed at autopsy). ${ }^{23}$ All patients who were residents of Southern Alberta and diagnosed with histologically confirmed medulloblastoma from January 1, 1975 to December 31, 1996 were included in the review. In addition, we also reviewed hospital records and pathology reports from the only three hospitals in Southern Alberta where neurosurgical procedures were performed between April 1, 1991 and December 31, 1996 and we reviewed the minutes from weekly pediatric and adult neuro-oncology rounds. These meetings are multidisciplinary tumor board rounds where new neuro-oncology patients are reviewed. Virtually all brain tumor patients requiring radio-or chemotherapy are presented and the minutes recorded. The adult and pediatric rounds began on January 1, 1994 and September 1, 1992 , respectively. We found no new cases of medulloblastoma using these last two methods that were not otherwise identified by the Alberta Cancer Registry. In total, 49 cases were identified during the 21 year study period.

\section{Pathological Characteristics}

A single neuropathologist (NBR) reviewed the histologic sections and microscopic characteristics described. All biopsy material was fixed in neutral buffered formalin, embedded in paraffin, and 3-5 micron sections were stained with hematoxylin and eosin. The tumors were classified according to Burger and Schiethauer. ${ }^{24}$ In 46 patients, tissue blocks were available for immunohistochemical staining to identify the tumor phenotype. Special stains used included PGP (protein gene product) 9.5, Synaptophysin, Reticulin, and GFAP (glial fibrillary acidic protein).

\section{Staging and Treatment}

Pre- and post-operative radiological evaluation consisted of either computed tomography (CT) (46 cases) and/or magnetic resonance imaging (MRI) (11 cases), which were reviewed by neuroradiologists. Two patients did not have postoperative imaging.

The extent of surgical resection of the tumors was determined from a combination of the surgeon's post-operative report (49 cases) and from the postoperative imaging performed within the first five postoperative days (47 cases). Data was extracted from radiology reports in most of our patients; the films were only available for re-review in 15 patients. Gross total resection was defined as that with a postoperative residual tumor $<1.5 \mathrm{~cm}^{2}$.

The post-operative risk stage of patients were graded as 'good' or 'poor' risk based on the type of surgical procedure performed and evidence of tumor outside the posterior fossa by craniospinal imaging. ${ }^{25}$ Good-risk patients were those whose tumor was confined to the primary area and who had undergone a gross total resection. Poor-risk patients were those who underwent subtotal resection of the primary lesion, those who had evidence of tumor dissemination outside of the posterior fossa, or those who did not have a complete evaluation of their spinal axes. The Chang staging system was also used to assess patients in our study. ${ }^{26}$

\section{Incidence Rates and Statistical Analyses}

The two endpoints used in this study were overall survival and progression-free survival. The overall survival was estimated by using the date of death or the last date on which the patient was known to be alive. Survival probabilities were calculated by the Kaplan-Meier method. ${ }^{27}$ Log-rank statistics ${ }^{28}$ 
were used to test the strength of association between overall survival or disease-free survival and a single variable.

\section{RESULTS}

\section{Incidence}

The crude annual incidence rate of medulloblastoma was $0.216 / 100,000$ for all ages, $0.557 / 100,000$ for children, and 0.094 $/ 100,000$ for adults, respectively. This represented $4 \%$ of all malignant brain tumors diagnosed during the period.

\section{Patient Characteristics}

A total of 49 patients were included in the study and their medical records were reviewed. Their clinical and treatment characteristics are presented in Table 1 . Of the 49 patients, 30 $(61 \%)$ were children (age <16), and 19 patients $(39 \%)$ were adults (age $\geq 16)$. In children, $18(60 \%)$ were male and $12(40 \%)$ were female. In adults, $12(63 \%)$ were male and $7(37 \%)$ were female. The mean ages at the diagnosis of medulloblastoma were seven years for children and 29.2 years for adults. The most common symptoms at the time of initial examination were those associated with increased intracranial pressure and cerebellar dysfunction including headache $(80 \%)$, nausea /vomiting $(78 \%)$ and ataxia $(73 \%)$.

Table 1: Clinical and treatment characteristics in medulloblastoma patients

\begin{tabular}{|c|c|c|c|}
\hline & $\begin{array}{c}\text { \# Patients Overall } \\
(n=49)\end{array}$ & $\begin{array}{c}\text { \# Children } \\
\text { (Age <16, } \\
n=30,61 \%)\end{array}$ & $\begin{array}{c}\text { \# Adults } \\
\text { (Age } \geq 16, \\
n=19,39 \%)\end{array}$ \\
\hline \multicolumn{4}{|l|}{ Age (years) } \\
\hline Mean & 15.5 & 6.9 & 29.2 \\
\hline Range & $1.1-44.4$ & $1.1-15.8$ & $16.3-44.4$ \\
\hline \multicolumn{4}{|l|}{$\operatorname{Sex}[n(\%)]$} \\
\hline Male & $30(61 \%)$ & $18(60 \%)$ & $12(63 \%)$ \\
\hline Female & $19(39 \%)$ & $12(40 \%)$ & $7(37 \%)$ \\
\hline \multicolumn{4}{|l|}{ Presenting Symptoms $[n(\%)]$} \\
\hline Duration (median, range) & $53(35$ to 112$)$ & 44 (23 to 90$)$ & 75 (49 to 142$)$ \\
\hline Headache & $39(80 \%)$ & $23(77 \%)$ & $16(84 \%)$ \\
\hline Nausea and vomiting & $38(78 \%)$ & $25(83 \%)$ & $13(68 \%)$ \\
\hline Ataxia & $36(73 \%)$ & $21(70 \%)$ & $15(79 \%)$ \\
\hline Altered consciousness & $17(35 \%)$ & $16(53 \%)$ & $1(5 \%)$ \\
\hline \multicolumn{4}{|l|}{ Chang Staging $[n(\%)]$} \\
\hline $\mathrm{T} 1$ & $7(14 \%)$ & $2(7 \%)$ & $5(26 \%)$ \\
\hline $\mathrm{T} 2$ & $15(31 \%)$ & $9(30 \%)$ & $6(32 \%)$ \\
\hline T3 & $21(43 \%)$ & $17(57 \%)$ & $4(21 \%)$ \\
\hline Unknown & $6(12 \%)$ & $2(7 \%)$ & $4(21 \%)$ \\
\hline \multicolumn{4}{|l|}{ Post-Operative Status [ $n(\%)]$} \\
\hline Good Risk & $13(27 \%)$ & $6(20 \%)$ & $7(37 \%)$ \\
\hline Poor Risk & $32(65 \%)$ & $23(77 \%)$ & $9(47 \%)$ \\
\hline Unknown Risk & $4(8 \%)$ & $1(3 \%)$ & $3(16 \%)$ \\
\hline \multicolumn{4}{|l|}{ Treatment $[n(\%)]$} \\
\hline \multicolumn{4}{|l|}{ Surgery } \\
\hline GTR & $16(33 \%)$ & $7(23 \%)$ & $9(47 \%)$ \\
\hline RSTR & $16(33 \%)$ & $13(43 \%)$ & $3(16 \%)$ \\
\hline STR & $16(33 \%)$ & $10(34 \%)$ & $6(31 \%)$ \\
\hline unknown & $1(1 \%)$ & $0(0 \%)$ & $1(5 \%)$ \\
\hline Radiation Therapy & $47(96 \%)$ & $28(93 \%)$ & $19(100 \%)$ \\
\hline Chemotherapy & $17(35 \%)$ & $14(47 \%)$ & $3(16 \%)$ \\
\hline RT, Chemotherapy \& Surgery & $15(31 \%)$ & $12(40 \%)$ & $3(16 \%)$ \\
\hline \multicolumn{4}{|l|}{ Shunting } \\
\hline Yes & $22(45 \%)$ & $19(63 \%)$ & $3(16 \%)$ \\
\hline No & $22(45 \%)$ & $8(27 \%)$ & $14(74 \%)$ \\
\hline Unknown & $5(10 \%)$ & $3(10 \%)$ & $2(10 \%)$ \\
\hline
\end{tabular}

Abbreviations: GTR - gross total resection, RSTR - radical subtotal resection, RT - radiation therapy, STR - subtotal resection.

\section{Imaging Features}

Computed tomography scanning was used in 36 patients (73\%), both MR imaging and CT scanning were done in 10 patients, and MRI imaging alone was done in one patient. Contrast enhancement was present in the majority of the CT scans (32). Other radiologic features included mass effect, hydrocephalus, calcification, and cystic components. The tumor size was not available because tumor volumes were not routinely recorded. The presence or absence of hydrocephalus was recorded in all patients: 35 patients $(71 \%)$ had hydrocephalus, 22 patients $(45 \%)$ underwent insertion of a ventricular peritoneal shunt before undergoing radiation therapy. The 13 other patients with hydrocephalus did not require a shunt after surgical resection.

\section{Histological Features}

All 49 cases were confirmed to be medulloblastoma by histological criteria. The predominant pathology consisted of densely packed cells with round-to-oval hyperchromatic nuclei surrounded by scanty cytoplasm. The cells were often arranged in sheets. Rosettes were typically present $(55.1 \%)$ but were not a constant feature. The majority of the tumors were undifferentiated $(67.4 \%)$ and small cell $(65.3 \%)$. Occasionally a large cell variation was found $(8.2 \%)$. Some of the tumors demonstrated cellular differentiation along glial, nodular (desmoplastic) and neuronal cell lines, while a few showed mixed characteristics. Necrosis was evident in 34/49 (69.4\%). In six tumors the necrosis was extensive and another seven demonstrated palisading type of necrosis. Mitoses were seen in 48/49 (98\%) cases.

\section{Treatment Characteristics}

All patients underwent surgery: $16(33 \%)$ had a gross total resection, 16 had a radical subtotal resection, 16 had a subtotal resection and the extension of surgery could not be evaluated in one case. Overall, 13 patients (27\%) were classified as "goodrisk" and $32(65 \%)$ as "poor-risk; 4 patients (8\%) were "unknown-risk" because of missing information. According to the Chang staging system there were 7 patients with stage T1 disease, 15 with T2, 21 with T3, and 6 patients were classified as "unknown".

Forty-seven patients (96\%) underwent adjuvant radiation therapy following surgery (adults, $n=19$, children $n=28$ ). In contrast, only 17 patients (35\%) received adjuvant chemotherapy; most of these were children. Only 15 patients (31\%) had multi-modality treatment consisting of surgery, radiation and chemotherapy. Twenty two patients $(45 \%)$ had a ventriculo-peritoneal shunt insertion for hydrocephalus; most of these were children.

\section{Recurrence}

Twenty-eight (57\%) patients had evidence of disease progression, one additional patient died from their disease but information regarding the details of the recurrence was unavailable. Overall, the median time to recurrence was 22.4 months (range; 6.4-192.3). The median survival time following recurrence was only 9.3 months (range; 0.4-64.9). The sites of tumor recurrence (Table 2) were local (29\%), spine only (18\%), 
Table 2: Features of medulloblastoma patients at tumor recurrence

\begin{tabular}{|c|c|c|c|}
\hline & $\begin{array}{c}\text { \# Patients } \\
\text { Overall } \\
(n=28)\end{array}$ & $\begin{array}{l}\text { \# Children (Age } \\
<16, n=15,50 \% \text { ) }\end{array}$ & $\begin{array}{c}\text { \# Adults } \\
\text { (Age } \geq 16, n=13, \\
68 \%)\end{array}$ \\
\hline \multicolumn{4}{|c|}{ Recurrence Time (months) } \\
\hline Median $(n=23) *$ & 22.4 & 14.5 & 33.6 \\
\hline Range & $6.4-192.3$ & $6.4-192.3$ & $6.8-83.4$ \\
\hline \multicolumn{4}{|c|}{ Survival Post-Recurrence (months) } \\
\hline Median $(\mathrm{n}=23)^{*}$ & 9.3 & 9.3 & 10.1 \\
\hline Range & $0.4-64.9$ & $0.4-26.0$ & $1.2-64.9$ \\
\hline \multicolumn{4}{|c|}{ Recurrence Site $[n(\%)]$} \\
\hline Local & $8(29 \%)$ & $5(33 \%)$ & $3(23 \%)$ \\
\hline Local \& spine & $3(11 \%)$ & $1(7 \%)$ & $2(15 \%)$ \\
\hline Spine & $5(18 \%)$ & $2(13 \%)$ & $3(23 \%)$ \\
\hline Subfrontal & $3(11 \%)$ & $2(13 \%)$ & $1(8 \%)$ \\
\hline Brain & $1(3 \%)$ & $1(7 \%)$ & $0(0 \%)$ \\
\hline Brain \& spine & $1(3 \%)$ & $0(0 \%)$ & $1(8 \%)$ \\
\hline CSF spread & $2(7 \%)$ & $2(13 \%)$ & $0(0 \%)$ \\
\hline Unknown & $5(18 \%)$ & $2(13 \%)$ & $3(24 \%)$ \\
\hline
\end{tabular}

Abbreviations: CSF - cerebrospinal fluid, NAD - no active disease

$*$ information not available for 5 patients

local and spine (11\%), sub-frontal (11\%), CSF cytology (7\%). The success of salvage therapy for recurrent disease was poor in our series. Salvage treatments included surgery, further radiotherapy, chemotherapy, or a combination. Three patients with recurrent tumors also received high dose-chemotherapy and autologous stem cell transplantation. Due to the small number of

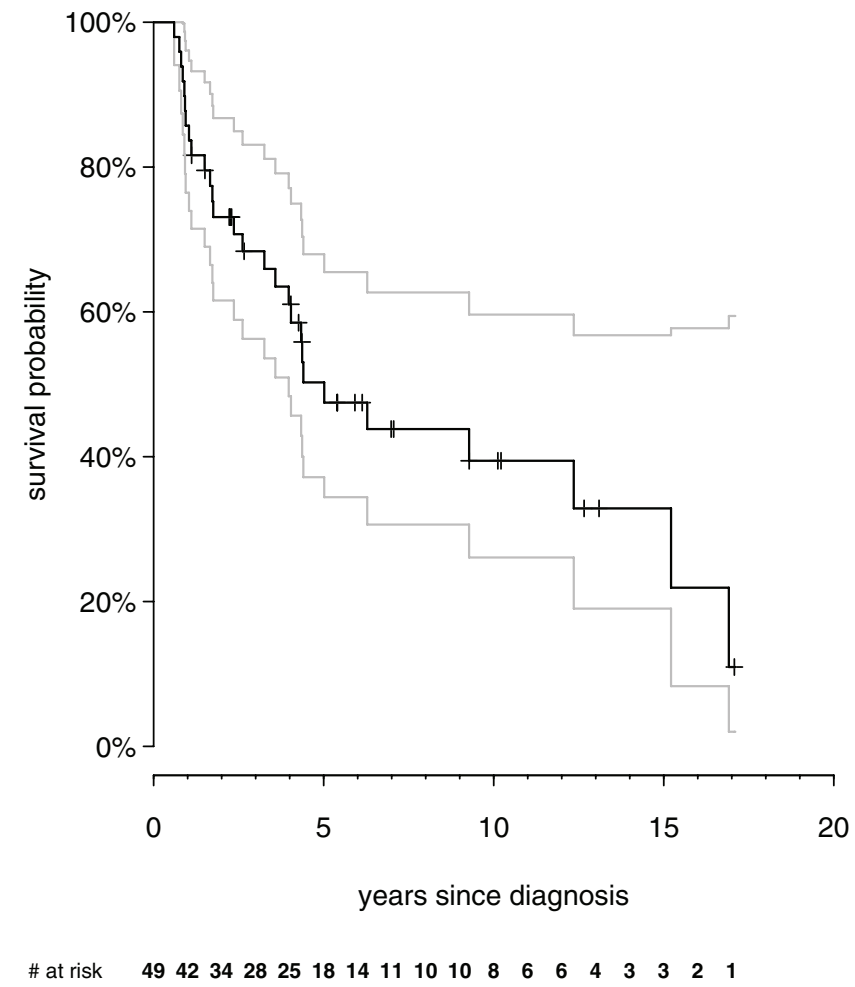

Figure: Kaplan-Meier survival curve (with $95 \%$ confidence intervals) for patients with medulloblastoma diagnosed from 1976 to 1996. patients and multiple treatment regimens used, it was not possible to show a benefit for any particular therapy.

\section{Survival \& Prognostic factors}

The five-year actuarial survival rate was $50.3 \%$ for entire groups of patients, $55.7 \%$ for children and $44.1 \%$ for adults (Figure). There was a trend for females to have a longer survival than males (five-year survival rate of $91 \%$ versus 19\%). Table 3 shows the five-year survival rates according to age, gender, resection, indication of chemotherapy and shunt. These parameters were evaluated for prognostic importance. The only prognostic variable, which only approached statistical significance, was the extent of resection, favoring gross total resection/subtotal resection over less complete resection $(\mathrm{p}=$ 0.06, Log Rank Test).

\section{Collin's Law Violators}

Three patients $(6.1 \%)$, all diagnosed as children (10\% of $<16$ years-of-age), developed recurrent tumors following prolonged periods of remission and were considered "Collin's Law Violators" (Table 4). These three patients represented $21.4 \%$ of children who were initially thought to be long-term survivors. All patients were male. One patient was classified as good risk, he had a gross total resection of the tumor. The other two were considered poor risk patients, had subtotal tumor resections and both had shunts inserted at first presentation. All three patients had received full craniospinal irradiation with posterior fossa boost; two had adjuvant chemotherapy.

The tumors recurred at 5, 16 and 13 years after their initial diagnosis. Recurrence was either local or limited to the posterior fossa. All of them had repeat surgery. Contrary to our expectations, all patients had recurrent medulloblastomas rather

Table 3: Prognostic variables

\begin{tabular}{lcc}
\hline & $\begin{array}{c}\text { Five Year Survival } \\
\text { Estimate (95\% CI) }\end{array}$ & Log Rank Test \\
\hline All patients $(\boldsymbol{n}=\mathbf{4 9})$ & $50.3 \%(35.1,65.4)$ & \\
$\begin{array}{l}\text { Age (years) } \\
<16(n=30)\end{array}$ & $\mathrm{p}=0.26$ \\
$\geq 16(n=19)$ & $55.7 \%(36.4,75.0)$ & \\
& $44.1 \%(20.6,67.5)$ & \\
Gender & & $\mathrm{p}=0.35$ \\
$\quad$ Male $(n=30)$ & $47.1 \%(28.2,65.9)$ & \\
Female $(n=19)$ & $55.3 \%(29.4,81.1)$ & \\
& & $\mathrm{p}=0.06$ \\
Resection & & \\
$\quad$ GTR $(n=32)$ & $60.5 \%(44.3,82.5)$ & \\
STR/BX/unknown $(n=17)$ & $35.3 \%(18.5,67.2)$ & $\mathrm{p}=0.35$ \\
Chemotherapy & & \\
$\quad$ Yes $(n=17)$ & $61.3 \%(40.7,92.3)$ & $\mathrm{p}=0.23$ \\
No $(n=32)$ & $46.2 \%(31.1,68.6)$ & \\
Shunt & & \\
Yes $(n=22)$ & $59.9 \%(41.6,86.2)$ & \\
No/unknown $(n=27)$ & $42.4 \%(17.6,65.2)$ &
\end{tabular}

Abbreviations: BX - biopsy, GTR - gross total resection, STR - subtotal resection. 


\section{Table 4: Characteristics of Collins' Law Violators}

\begin{tabular}{lccc}
\hline & CLV \#1 & CLV \#2 & CLV \#3 \\
\hline Initial Features & & & \\
Age at diagnosis (years) & 1 & 14 & 8 \\
Sex & $\mathrm{M}$ & $\mathrm{M}$ & $\mathrm{M}$ \\
Chang stage - tumor/met & $\mathrm{T} 1 / \mathrm{M} 0$ & $\mathrm{~T} 1 / \mathrm{M} 0$ & T3A/M0 \\
Good/poor risk & poor & good & poor \\
Symptom duration (months) & 2.0 & 0.5 & 2.5 \\
Surgery type & $\mathrm{STR}$ & $\mathrm{GTR}$ & $\mathrm{RSTR}$ \\
RT field & $\mathrm{C}$ \& \& PF boost & C-S \& PF boost & C-S \& PF boost \\
RT dose in posterior fossa (cGy) & 5320 & 3400 & 5640 \\
Adjuvant chemotherapy & POG 8633 & lomustine & no \\
Shunt & Yes & no & yes \\
& & & \\
Recurrence & $6(5)$ & 31 (16) & 21 (13) \\
Age (delay from onset in years) & Local & local & PF \\
Site of recurrence & STR & biopsy & STR \\
Repeat surgery & no & no & yes \\
Repeat radiotherapy & cyclophosphamide & carmustine, & Stem cell transplant and \\
Chemotherapy & & vincristine & cisplatin, etoposide, \\
& & & cyclophosphamide \\
& & & \\
& 15 & 11 & 28 \\
Survival post recurrence (months) & & & \\
\hline
\end{tabular}

Abbreviations: CLV-Collins Law Violator, C-S-craniospinal, GTR gross total resection, PF-posterior fossa, RT-radiation therapy, POGpediatric oncology group, STR-subtotal resection, RSTR-radical subtotal resection.

than radiation-induced neoplasms (eg., sarcoma, [glioblastoma multiforme] GBM and meningiomas). All three patients underwent postoperative chemotherapy, with high dosage chemotherapy and stem cell transplantation in two. The prognosis after recurrence was poor with a median survival of only 15 months with no significant differences between the CLV's and the other non-CLV recurrence patients.

\section{DISCUSSION}

We conducted this study to estimate the survival rate, prognostic factors and frequency of CLVs in an unselected, population-based study of patients with medulloblastoma in order to eliminate the selection bias inherent in other case series and institutional reviews. In this study, all histologic and clinical information were reviewed to confirm the accuracy of the data. This is an important issue because histologic diagnoses are often inaccurate in cancer registries. Although our overall incidence of medulloblastomas $(0.194 / 100,000)$ (population of Alberta in 1996 was 2.8 million) in our population-based study was similar to those reported by others, ${ }^{29,30}$ we found a relative higher than expected incidence of medulloblastomas in adults $(0.094 / 100,000)$. Not surprisingly, the five-year survival rate $(50 \%)$ in our population-based study was lower than in "single institution" series which found five-year survival rates of 86$93 \% .{ }^{11,15}$ Our survival rates are similar to other population-based studies that ranged from $36 \%$ to $60 \%$ at five years. ${ }^{29,31,32}$ The most concerning aspect of the survival curves we estimated was that it did not "level off", suggesting patients have a life time risk of tumor recurrence and should not be considered cured. Finally, we did not find Collin's Law to be a useful concept in medulloblastoma patients and suggest it be abandoned. ${ }^{20,33}$ The most common cause of a recurrent enhancing mass was recurrent tumor and not radiation-induced necrosis or a radiation-induced neoplasm.
As a retrospective, population-based study spanning 21 years our study has several limitations. First, significant conclusions regarding treatment can't be made since treatment was quite heterogeneous, during this period of time and information regarding some maneuvers is incomplete. For example, the evaluation of extent of resection by neurosurgeons is notoriously inaccurate though other retrospective series have concluded that a gross total resection is associated with favorable survivals..$^{34,35}$ In addition, the small size of our study also limits our comments regarding treatment.

Similarly, conclusions regarding other prognostic factors are also limited due to the low statistical power of our study. The power is low because the sample size is small and treatment/staging information is highly variable in retrospective series. For example, we did not detect an effect of gender on survival, as reported by others. ${ }^{30,36}$ Nor did we find that tumors arising in the lateral cerebellar hemisphere had a superior prognosis to those arising in the vermis, probably due to the ease of surgical removal in the lateral hemispheres. ${ }^{37}$ Definitive conclusions regarding treatment and prognostic factors will await the completion of large prospective clinical trials which include standardized data collection and uniform treatments.

A final limitation of our study is that no molecular analyses were performed as these reagents were not available for paraffin sections when the patients were treated or this study performed. Little is known about the molecular genetic events that lead to the development of medulloblastoma. Mutation in the p53 gene, ${ }^{38-40}$ amplification of c-myc ${ }^{41}$ and $\mathrm{N}$-myc, ${ }^{42}$ upregulation of different PAX genes, ${ }^{43}$ and patched ${ }^{40,44}$ have all been implicated in the pathogenesis of the tumor. In addition, high levels of expression of TrkC has been associated with a much better prognosis. ${ }^{45}$ More recently, with the identification of molecular prognostic factors such as isochromosome $17 \mathrm{q}^{46}$ and the application of new genomic techniques, the identification of medulloblastoma subgroups that are enriched for specific genetic alterations could be useful in the selection of patients for future clinical trials of molecular targeted therapies. ${ }^{47}$

\section{ACKNOWLEDGements}

This study was supported by the Alberta Cancer Board. We thank our patients and their families for participating in this study.

\section{REFERENCES}

1. Cumberlin RL, Luk KH, Wara WM, Sheline GE, Wilson CB. Medulloblastoma: treatment results and effect on normal tissues. Cancer. 1979;43:1014-20.

2. Miltenburg D, Louw DF, Sutherland GR. Epidemiology of childhood brain tumors. Can J Neurol Sci. 1996;23:118-22.

3. Carrie C, Lasset C, Blay JY, Nrgrier S, Bouffet E, Barbet N, et al. Medulloblastoma in adults: survival and prognostic factors. Radiother Oncol. 1993;29:301-7.

4. Brandes AA, Paris MK. Review of the prognostic factors in medulloblastoma of children and adults. Crit Rev Oncol Hematol. 2004;5:121-8.

5. Herrlinger U, Steinbrecher A, Rieger J, Hau P, Kortmann RD, Meyermann R, et al. Adult medulloblastoma: prognostic factors and response to therapy at diagnosis and at relapse. J Neurol. 2005;252(3):291-9.

6. Eisenstat DD. Clinical management of medulloblastoma in adults. Expert Rev Anticancer Ther. 2004;4:795-802. 
7. Kopelson G, Linggood RM, Kleinman GM. Medulloblastoma in adults: improved survival with supervoltage radiation therapy. Cancer. 1982;49:1334-7.

8. Ribi K, Relly C, Landolt MA, Alber FD, Boltshauser E, Grotzer MA. Outcome of medulloblastoma in children: long-term complications and quality of life. Neuropediatrics. 2005;36: 357-65.

9. Rutkauskiene G, Labanauskas L, Jarusevicius L. The results of the treatment of childhood medulloblastoma with radiotherapy at Kaunas University of Medicine Hospital in 1994-2000. Medicina (Kaunas). 2006; 42:22-32.

10. Gajjar A, Chintagumpala M, Ashley D, Kellie S, Kun LE, Merchant TE, et al. Risk-adapted craniospinal radiotherapy followed by high-dose chemotherapy and stem-cell rescue in children with newly diagnosed medulloblastoma (St Jude medulloblastoma96): long-term results from a prospective, multicentre trial. Lancet Oncol. 2006;7(10):813-20.

11. Packer RJ, Gajjar A, Vezina G, Rorke-Adams L, Burger PC, Robertson PL, et al. Phase III study of craniospinal radiation therapy followed by adjuvant chemotherapy for newly diagnosed average-risk medulloblastoma. J Clin Oncol. 2006;24(25): 4202-8.

12. Geyer JR, Sposto R, Jennings M, Boyett JM, Axtell RA, Breiger D, et al. Multiagent chemotherapy and deferred radiotherapy in infants with malignant brain tumors: a report from the Children's Cancer Group. J Clin Oncol. 2005;23:7621-31.

13. Mulhern RK, Palmer SL, Merchant TE, Wallace D, Kocak M, Brouwers P, et al. Neurocognitive consequences of risk-adapted therapy for childhood medulloblastoma. J Clin Oncol. 2005;23:5511-19.

14. Grill J, Sainte-Rose C, Jouvet A, Gentet JC, Lejars O, Frappaz D, et al. Treatment of medulloblastoma with postoperative chemotherapy alone: an SFOP prospective trial in young children. Lancet Oncol. 2005;6:573-80.

15. Rutkowski S, Bode U, Deinlein F, Ottensmeier H, Warmuth-Metz $\mathrm{M}$, Soerensen $\mathrm{N}$, et al. Treatment of early childhood medulloblastoma by postoperative chemotherapy alone. N Engl J Med. 2005;352:978-86.

16. Collins VP. Wilms' tumor: its behavior and prognosis. J Louisiana State Med Soc. 1955;107:474-80.

17. Brown WD, Tavare CJ, Sobel EL, Gilles FH. The applicability of Collins' Law to childhood brain tumors and its usefulness as a predictor of survival. Neurosurgery. 1995;36:1093-6.

18. Paulino AC. Collins' law revisited: can we reliably predict the time to recurrence in common pediatric tumors? Pediatr Hematol Oncol. 2006;23(1):81-6.

19. Brown WD, Tavare J, Sobel EL, Gilles FH. Medulloblastoma and Collin's law: a critical review of the concept of a period of risk for tumor recurrence and patient survival. Neurosurgery. 1995;36:691-7.

20. Lefkowithz IB, Packer RJ, Ryan SG, Shah N, Alavi J, Rorke LB, et al. Late recurrence of primitive neuroectodermal tumor/ medulloblastoma. Cancer. 1988; 62(4):826-30.

21. World Health Organization, editors. International classification of diseases for oncology (ICD-0) 2. 1990 Geneva: World Health Organization.

22. World Health Organization, editors. International classification of diseases 9th revision clinical modification (ICD-9-CM) 8. 1991 Geneva: World Health Organization.

23. Cancer Programs Regulation. Alberta Reg. 242/1998. Database online. [updated 2006 September 26; cited 2006 October 10] Available from http://www.canlii.org/ab/laws/regu/1998r.242/ 20060926/whole.html.

24. Burger PC, Scheithauer BW. Tumors of the nervous system, 3rd series. Washington D.C: Armed Forces Institute of Pathology; 1994

25. Le QT, Weil MD, Wara WM, Lamborn KR, Prados MD, Edwards MS, et al. Adult medulloblastoma: an analysis of survival and prognostic factors. Cancer J Sci Am. 1997;3:238-45.

26. Chang $\mathrm{CH}$, Housepian EM, Herbert C. An operative staging system and a megavoltage radiotherapeutic technic for cerebellar medulloblastoma. Radiology. 1969;93:1351-9.
27. Kaplan EL, Meier P. "Nonparametric estimation from incomplete observations." J Am Stat Assoc. 1958; 53:457-81.

28. Mantel N. The detection of disease clustering and a generalized regression approach. Cancer Res. 1967;27:209-20.

29. Davis FG, Freels S, Grutsch J, Barlas S, Brem S. Survival rates in patients with primary malignant brain tumors stratified by patient age and tumor histological type: an analysis based on surveillance, Epidemiology, and End Results (SEER) data, 19731991. J Neurosurgery. 1998;88:1-10.

30. Farwell JR, Dohrmann GJ, Flannery JT. Medulloblastoma in childhood: an epidemiological study. J Neurosurgery. 1984;61: 657-64.

31. Agerlin N, Gjerris F, Brincker H, Haase J, Laursen H, Moller KA, et al. Childhood medulloblastoma in Denmark 1960-1984. A population-based retrospective study. Childs Nerv Syst. 1999; 15(1):29-36

32. Alston RD, Newton R, Kelsey A, Newbould MJ, Birch JM, Lawson B, et al. Childhood medulloblastoma in northwest England 1954 to 1997: incidence and survival. Dev Med Child Neurol. 2003;45(5):308-14.

33. Nishio S, Morioka T, Takeshita I, Fukui M. Medulloblastoma: survival and late recurrence after the Collins' risk period. Neurosurg Rev. 1997;20(4):245-9.

34. Bloom HJG, Bessell EM. Medulloblastoma in adults: a review of 47 patients treated between 1952 and 1981. Int J Radiat Oncol Biol Phys. 1990;18:763-72.

35. Akay KM, Izci Y, Baysefer A, Atabey C, Kismet E, Timurkaynak E. Surgical outcomes of cerebellar tumors in children. Pediatr Neurosurg. 2004;40:220-5.

36. Tabori U, Sung L, Hukin J, Laperriere N, Crooks B, Carret AS, et al. Distinctive clinical course and pattern of relapse in adolescents with medulloblastoma. Int J Radiat Oncol Biol Phys. 2006;64(2):402-7.

37. Robert RO, Lynch CF, Jones MP, Hart MN. Medulloblastoma: a population based study of 532 cases. J Neuropathol Exp Neurol. 1991;50:134-44.

38. Cogen PH, MacDonald JD. Tumor suppressor genes and medulloblastoma. J Neurooncology. 1996;29:103-12.

39. Malkin D, Li FP, Strong LC, Fraumeni JJ, Nelson CE, Kin DH, et al. Germline p53 mutations in a familial syndrome of breast cancer, and other neoplasms. Science. 1990;250: 1233-8.

40. Uziel T, Zindy F, Xie S, Lee Y, Forget A, Magdaleno S, et al. The tumor suppressors Ink $4 \mathrm{c}$ and p 53 collaborate independently with Patched to suppress medulloblastoma formation. Genes Dev. 2005; 19:2656-7.

41. Badiali M, Pession A, Basso G, Andreini L, Rigobello L, Gallassi $\mathrm{E}$, et al. N-myc and c-myc oncogenes amplification in medulloblastomas. Evidence of a particularly aggressive behavior of a tumor with c-myc amplification. Tumor. 1991;77:118-21.

42. Tomlinson FH, Jenkins RB, Scheithauer BW, Keelan PA, Ritland S, Parisi JE, et al. Aggressive medulloblastoma with high-level Nmyc amplification. Mayo Clinic Proceed. 1994;69:359-65.

43. Kozmik Z, Sure U, Ruedi D, Busslinger M, Aguaai A. Deregulated expression of PAX5 in medulloblastoma. Proc Nat'l Acad Sci USA. 1995;92:5709-13.

44. Groodrich LV, Milenkovic L, Higgins KM, Scott MP. Altered neural cell fates and medulloblastoma in mouse patched mutants. Science. 1997; 277:1109-13.

45. Grotzer MA, Janss AJ, Fung KM, Biegel JA, Sutton LN, Rorke LB, et al. Trk C expression predicts good clinical outcome in primitive neuroectodermal brain tumors. J Clin Oncol. 2000; 18:1027-35.

46. Pan E, Pellarin M, Holmes E, Smirnov I, Misra A, Eberhart CG, et al. Isochromosome $17 \mathrm{q}$ is a negative prognostic factor in poorrisk childhood medulloblastoma patients. Clin Cancer Res. 2005;11:4733-40.

47. Thompson MC, Fuller C, Hogg TL, Dalton J, Finkelstein D, Lau $\mathrm{CC}$, et al. Genomics identifies medulloblastoma subgroups that are enriched for specific genetic alterations. J Clin Oncol. 2006;24:1924-31. 